\title{
EDITORIAL
}

\section{Fórum Nacional de Pesquisa e Pós-Graduação Stricto Sensu em Fisioterapia}

\author{
Prezados Colegas,
}

Em junho de 2006 a Universidade Federal de Minas Gerais em Belo Horizonte, terá a honra de sediar o II Fórum Nacional de Pesquisa e Pós-Graduação Stricto Sensu em Fisioterapia. Este é o evento maior da Associação Brasileira de Pesquisa e Pós-Graduação em Fisioterapia, criada em maio de 2005.

Nesta oportunidade fisioterapeutas desenvolvendo atividades de pesquisas em programas da área 21 da Capes, área à qual estão vinculados os programas de Fisioterapia; ou em outras áreas afins, poderão se encontrar e discutir assuntos de interesse comuns contribuindo para o crescimento e consolidação da nossa pesquisa.

Neste sentido, o evento tem como objetivos específicos:

$\checkmark$ Discutir a participação dos órgãos de fomento na pesquisa e pós-graduação em Fisioterapia;

$\checkmark$ Diagnosticar e fundamentar estratégias para ampliação da pesquisa em Fisioterapia;

$\checkmark$ Estabelecer estratégias para a consolidação dos programas de Pós-Graduação em Fisioterapia;

$\checkmark$ Discutir a situação atual, os avanços do último ano e as perspectivas dos periódicos científicos da área;

$\checkmark$ Discutir a participação dos orgãos de classe na pesquisa e pós-graduação stricto sensu em Fisioterapia.

O II Fórum Nacional de Pesquisa e Pós-Graduação Stricto Sensu em Fisioterapia ocorrerá nos dias 21, 22 e 23 de junho e maiores informações podem ser obtidas pelo site www.fundep.ufmg.br.

Acreditamos que esta será uma oportunidade importante para que possamos, num esforço conjunto, encontrar caminhos que sejam produtivos e contribuam para a produção do conhecimento na Fisioterapia.

\section{Verônica Franco Parreira}

Coordenadora do Programa de Pós-Graduação em Ciências da Reabilitação da UFMG Presidente da Comissão Organizadora do II Fórum Nacional de Pesquisa e Pós-Graduação Stricto Sensu em 